\title{
The impact of minority ethnic businesses on the spatial character of London's high streets
}

\begin{abstract}
Research shows that a variety of building types, sizes and street morphologies can support a diversified mix of uses and thus contribute to the vitality of town centres. Other studies have highlighted the special role of minority ethnic businesses in this context. This study set out to examine the relationship between spatial accessibility, commercial diversity (as a measure of land use mixing) and minority ethnic business (MEB) diversity in ten of London's high streets.

We found that streets with a significant MEB presence were more likely to benefit from commercial diversity and that the sampled MEB units were measurably smaller in size. We also found the location of larger clusters of MEB businesses to be more accessible, both locally and across the city. The study also found three distinct types of MEB centres: ranging from high streets with a small MEB presence, others with a high rate of MEB mixing, and a third type: the 'ethnic marketplace', with a singular ethnic character.

We conclude that greater attention should be given to designing street accessibility, lot configuration, mixed building sizes, and land use mixing, in order to serve the long-term economic and social vitality of local town centres.
\end{abstract}

Authors:

1. Laura Vaughan, I.vaughan@ucl.ac.uk, 0203108 9042. Space Syntax Laboratory, Bartlett School of Architecture, University College London, London, WC1E 6BT. (Corresponding author).

2. Sadaf S Khan, sadaf.khan.11@ucl.ac.uk

3. Lusine Tarkhanyan, lusine.tarkhanyan@ucl.ac.uk

4. Ashley Dhanani, ashley.dhanani@ucl.ac.uk 


\section{Keywords}

space syntax, land use diversity, minority ethnic businesses, London, built form

\section{Introduction}

The local high street (the 'high street' is the primary commercial street in UK parlance, broadly equivalent to 'main street' in north America) is a multi-facetted and complex entity. It has to overcome the potential conflict of it serving both as a link to other places as well as place in which to remain (Jones et al, 2007). When designed well, local high streets can provide a wide range of goods and services for large numbers of people arriving on foot or by public transport. The importance of such places is not only economic: they can provide a local centre of interaction for the surrounding area in the form of a range of use types, from shops, banks and offices, through to schools and community functions (Griffiths, et al, 2008). London's high streets typically have a historical physical fabric, are a place of social, cultural, and political exchange as well as economic activity, functioning both as a movement corridor and means of communication through the city. They are likely to have multiple uses and ownership (Gort Scott and UCL Bartlett School of Planning, 2010). Older high streets constitute a distinctive and complex built form structure that supports socio-economic adaptability by virtue of their ability to support a variety of populations using a diverse mix of land use functions. This land use diversity stems from built form diversity, namely a mix of small and large buildings, ideally with a mix of tenures (Vaughan, 2015a; Törmä, et al, 2017). Successful high streets in the UK will typically have a combination of national chains alongside independent, entrepreneurial activity. Smaller businesses will hold measurable value for local communities in contrast with large scale developments as they provide both opportunities to develop businesses, specialised services, but also a "social economy of community and voluntary activity" (Dobson, 2016, p. 337). This brief overview suggests that urban form has a tangible role to play in providing a social space, as an information resource (see Penn et al., below), as an opportunity for work, or as a site of "social connections and interactions" (Watson, 2009, p. 1578). 
It is important to note that diversity is not simply a matter of mixing, but the spatial manner of this mixing is highly complex conceptually, as pointed out by Marcus and Colding (2014). The authors propose that diversity, along with variation of accessibility between locations (distance) and the ability of urban space to expand vertically (density) create the 'spatial capital' of an urban system. An urban system's resilience is supported, they argue, by subdivision of plots into smaller parcels, which naturally lead to a greater number of owners, uses and hence, agents of influence over activities in the area.

We define commercial diversity as a measure of the mixing of many different types of land uses within a tightly defined area. Putting the importance of land use mixing aside, small independent, minority ethnic businesses (MEBs) are increasingly contributing to local economies. The emergence of such businesses has been the result of a convergence of circumstances. The rise in unemployment amongst migrant communities, and the resultant lack of cultivation of skills required for more conventional employment in their new environment such as language proficiency and adequate education and career skills, means that minority immigrant groups will frequently resort to self-employment as a survival strategy (Barrett et al., 1996; lyer and Shapiro, 1999).

A well located ethnic marketplace serves as a point of interaction both within the group and outside of it (Hiebert et al., 2014, p. 5). Depending on the location and the way in which the street network is utilized, clusters of minority ethnic businesses can enable the intensification of communal activity, socialization, networking and self-support within a community (Vaughan, 2007; Hall, 2013).

Often due to the lack of skills required and low initial capital outlays, migrant businesses tend to occupy the lower end of the market in easy-to-enter businesses such as food retail, clothing and restaurants (Barrett et al., 1996; Hall, 2011; Kloosterman et al., 1999). Whilst this trend of self-employment may be the outcome of initial shortcomings in skills and/or a degree of prejudice and exclusion on the part of the host community, this entrepreneurial mind-set has proven to be advantageous to minority communities in providing employment for co-ethnics over time, in the form of a "protected market" (Aldrich et al., 1985) for the ethnic businesses and access to 
speciality items such as food, clothing, music and entertainment to ethnic minority groups who are looking to purchase products from home (lyer and Shapiro, 1999).

MEB owners have been known to militate against financial risk by subdividing and subletting space. This can result in adding diversity of land uses and creating complementary services on one site (Hall, 2011), yet it is important to note that areas of high ethnic diversity typically correspond to areas of deep deprivation. Given that deprivation is often related to a lack of accessibility to resources such as jobs, it is important to note research from Sweden which shows an association between spatial segregation and fewer opportunities to engage with a wider social network, especially for foreign-born people (Legeby, 2009). Whether this holds also for London is explored here. In addition, a previous theoretical review has argued that the ethnic marketplace is varied in its character (Vaughan, 2015b), ranging from the 'Latino' market of Wards Corner in Seven Sisters and Southall Broadway, both of which draw people from their immediate locality as well as from across the city to engage with their home culture; to Walworth Road in south London, with its multiplicity of nationalities, serving as an example of an emerging new phenomenon of the super-diverse landscape (Vertovec, 2006), where no single minority group stands out. This is one of several aspects of the MEB which we investigate empirically here. In the following section we elaborate the background to this study further.

\section{Background to the case}

London is a city where 179 nationalities are represented and 300 languages are spoken (Knowles, 2013). It exhibits high levels of ethnic diversity, especially in inner London boroughs (Paccoud, 2013). It has also been shown to be made up of a well-structured network of town centres and sub-centres (Hillier, 1999) and, as indicated in the introduction, there is an association between the longevity of a town centre, its land use diversity and its spatial adaptability (see also Vaughan et al, 2017). It is for these reasons that London was chosen as a focus for the study, which considered a sample of ten high streets and their immediate environs. The streets were selected to obtain a range of types defined by their residential ethnic composition, level of deprivation and land use diversity. 
This paper is the second of two publications that relate to a research project which took place during six months in 2016/17. In our earlier publication we used space syntax analysis of street network accessiblity in relation to the spatial distribution of MEBs. The results showed that high streets which contain a significant proportion of minority ethnic businesses are much more likely to be highly accessible to their surroundings than streets with a low MEB presence (Vaughan et al, 2017). Spatial integration often increased linearly with MEB presence, with high MEB presence high streets benefiting not only from local accessiblity, but also from good accessiblity at much high scales of travel, suggesting that they function not only as local high streets, but are also able to make the most of the spatial configuration of their location to serve people making trips from farther afield (while streets with low MEB presence tended to only serve their immediate vicinity). We suggested that these results relate to Hall's claim that minority ethnic commercial centres are located 'physically near to the centre but perceptually distant from it' (Hall 2011, p. 2572). Their high spatial integration allows for the footfall required for commercial viability whilst their perceptual location in the 'urban margins' provides an environment conducive to the emergence and presence of alternative cultures and economies.

These findings led us to investigate further the nature of commercial diversity. A previous study of land use diversity in the context of sustainability by Penn et al. (2009) found that cities provide a structured set of social, cultural and economic relations which help to shape patterns of diversity in urban areas - with a vital connection being made between a diversity of spatial structures (both built form and network accessiblity), a diversity of social, cultural and economic uses and behaviours, and a diversity of information provided by this dynamic setting. This argument, that an urban setting can be a 'generator' of innovation, led us to consider whether the nature of commercial diversity as being the outcome of these multiple spatial, social and economic forces was in any way related to the presence of minority ethnic businesses, which to date, have tended to be identified for their important socio-economic presence, but not much is understood about their dynamics as a physical presence on high streets, in terms of their numbers, juxtapositions between business types, and mixing. 
In contrast with conventional measures of high street success, which typically look broadly at commercial diversity defined as the mix of retail and office supply within a town centre (see e.g. BIS et al., 2011), here we were focused on an urban design approach to land uses: seeing them not only as a source of economic vitality, but wishing to consider the character of diversity as a sociospatial aspect of a high street in a socially diverse landscape. Rather than looking at broad-brush categories of use (such as retail or communal), we considered the finest grain of use type, country of origin of proprietor, the building size and frontage and - importantly - where and in what arrangement in relation to its neighbours it was positioned on the street. A diversity index for land use type (business diversity) as well as ownership (MEB diversity, defined by minority ethnic group) was constructed based on data gathered through direct observation of each high street block in the case study areas. Diversity indices are commonly used in ecological studies to measure the diversity of species in an area, but there are increasing calls for a more precise definition - beyond 'mixed use' in urban design analysis. Authors such as Perdikogianni and Penn (2006) have maintained the need to capture a more spatially detailed picture of the lived experience of walking down a high street, claiming that "attention needs to be paid to the location of uses and activities in relation to one another; the nature of users and premises; the pattern of comings and goings; the mix and balance of primary and other uses; the compatibility and synergy of uses; the intensity, density, permeability and grain of development; and to detail such as street layout and the ease of movement and density of footfall along routes". In other urban design related studies, especially in the field of health and place research, this approach is very common (e.g. Frank et al, 2005; Sarkar, et al, 2013). In this study we used this approach to identify the composition of high street blocks in terms of their land use types and MEBs. We explain the method in more detail in the Analysis section.

The first hypothesis for this study is that high MEB presence and diversity has a positive impact on the land-use mix in a local town centre. In other words, high streets which contain a large number of minority ethnic businesses with a wide range of 
business types are likely to correspond to greater availability of a range of products and service types within a given high street and that this will lead to adaptation of the built form itself (by, for example, subdividing existing buildings).

Given that the literature is split between sources which show that MEB high streets occur in areas of high deprivation due to the availability of a population more willing to shop on foot, with other sources stating that this is an outcome of the presence of a large captive minority ethnic residential population, we tested a second hypothesis, that a high incidence of MEB businesses corresponds to a relatively deprived population within walking distance (up to $2000 \mathrm{~m}$ ) from a high street.

This study therefore aimed to:

a) Document the number and mix of minority ethnic businesses (MEB) in local town centres as well as the spatial character of their buildings and streets (namely, hypothesis 1);

b) Explore the correspondence between the MEB character of each high street and high rate of deprivation within the residential population in its vicinity (namely, hypothesis 2 )

The following section details the study methods, after which we describe the results of the analysis. The paper ends with a discussion of findings, drawing conclusions on how a spatial reading of minority ethnic businesses can advance knowledge in the field of urban design studies.

\section{Methods}

This section will describe the case study selection method, followed by the description of the field observations of ethnic minority businesses across the high street and an overall description of the case studies. 


\section{Case study selection}

In order to analyse the relationship between MEB presence and population diversity and commercial diversity, a sample of local high streets was selected to represent a cross-section of socially deprived/affluent and ethnically diverse/homogenous residential neighbourhoods across London. The sample was chosen using the following parameters:

- The index of multiple deprivation (IMD), using the last (2011) census data at the level of Lower Layer Super Output Area (LSOA) geographical areas (each area contains around 1000-1500 inhabitants).

- The eighteen categories of ethnicity as defined by the Office of National Statistics (ONS) based on responses from the 2011 census that take into account multiple subgroups within five broad categories: 'White', 'Asian', 'Black', 'Mixed' and 'Other'.

The resulting cases were then divided into four groups according to either high or low deprivation and high or low socio-deprivation (filtering the top and bottom $20 \%$ of both ethnic diversity and the index of multiple deprivation). The town centres were further filtered by using land use diversity as the control variable, limiting the sample to all centres within the top $30 \%$ of land use diversity, defined as follows:

- Land use classes were defined using data at the level of census Output Areas (OA), the smallest level of area statistics available from the UK. These use thirteen categories [as per the Town and Country (Uses Classes) Order 1987]: commercial general, commercial agricultural, commercial industrial, commercial non-industrial, health and education, leisure and tourism, retail, retail food, food and drink, transport and a miscellaneous thirteenth category that includes land uses ranging from cash machines to waste disposal.

The final stage was to vary the selection geographically. In total five town centres were selected from inner London boroughs and five from outer London boroughs, with a spread around the points of the compass, resulting in the following cases: North Harrow in the north-west, Romford in the east, Southall to the west, Wimbledon Village in the south-west and Burnt Oak in the north of the city. Inner London centres included 
St John's Wood in the west, Bethnal Green to the east, Walworth Road in the south, Putney in the south-west and Deptford in the south easterly quadrant of the city.

In order to arrive at an objective selection of cases, we used town centre boundaries to find foci of retail and office activity across the sample. The boundaries are a UK national measure of the highest office and retail activity in an area (Astbury and ThurstainGoodwin, 2014). Although they exclude industrial activity, this is a limitation that is of lesser concern to this study's focus on street-facing businesses.

\section{Data gathering}

Once centres had been selected, a researcher recorded all non-residential activity along the high street within each centre. The extents of the high street were defined by identifying the location of the peak levels of non-residential activity, constraining this to length of the street situated between two major intersections that contained morphologically similar buildings. The latter were typically a row of attached buildings (namely, a terrace) with a predominance of commercial activity on the ground floor with two stories above - and - normally a maximum of two lanes of traffic. The researcher then surveyed all streets perpendicular to this section of the high street, stopping where continuous commercial activity stemming from the main high street ended (see example, Walworth Road, Peckham in Figure 1, which shows the extents of the survey for one of the ten sampled case studies). 


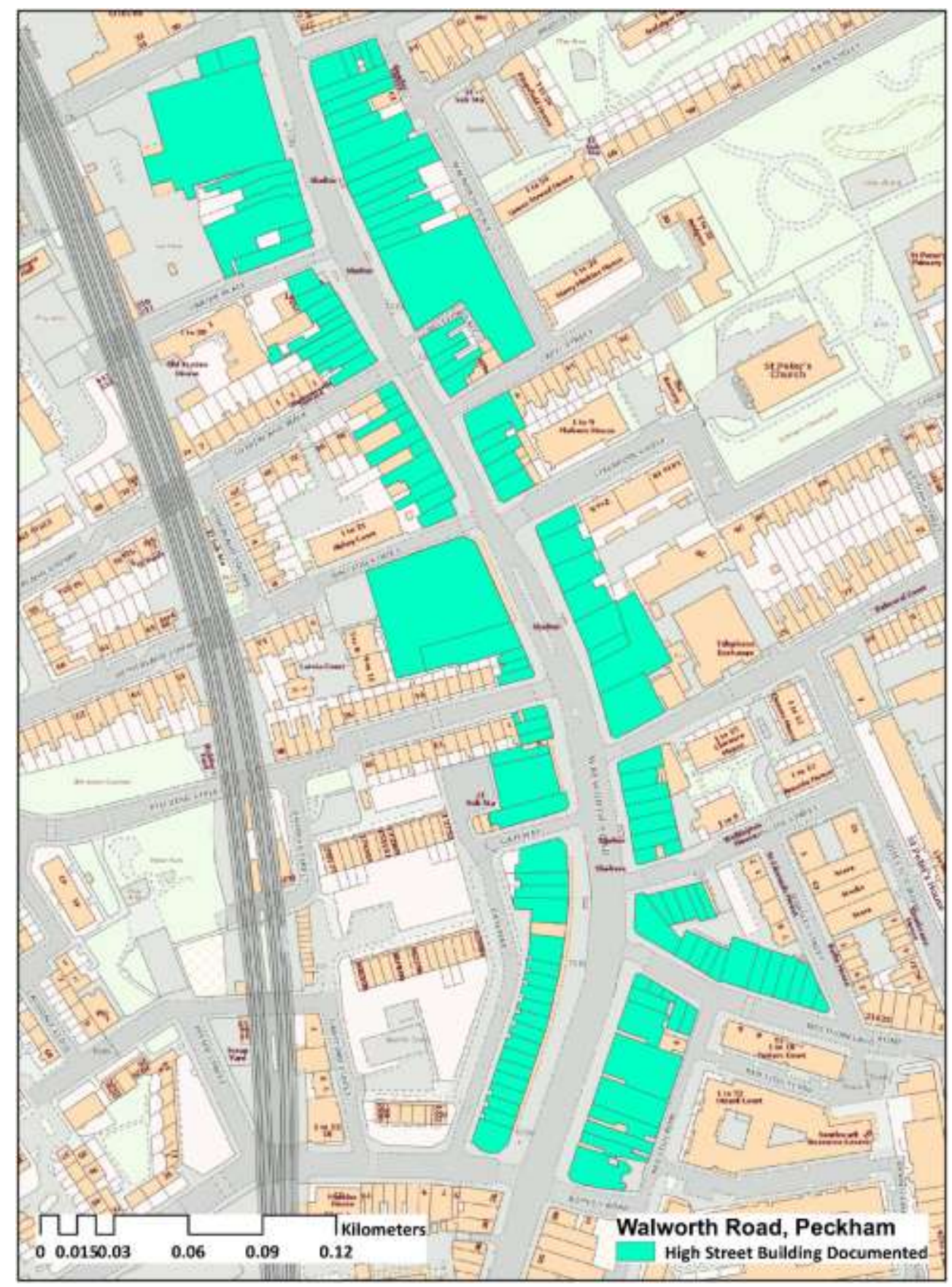

Figure 1. Example of mapping of building data for the case of Walworth Road, Peckham

This is a post-peer-review, pre-copyedit version of an article published in Urban Design International. The final authenticated version is available online at: https://doi.org/10.1057/s41289-018-0060-5. (c) The authors, UCL. 
This process of documentation was undertaken using Google Street View correct for 2015 as the primary source of observational data collection along with on-site visits to as many sites as practicable. These data were further supplemented by online sources in order to confirm the nature of the business and validate the type of commercial activity. We used All in London (http://www.allinlondon.co.uk) in all cases, and where available, "hyperlocal" blogs such as Deptford Dame (http://deptforddame.blogspot.co.uk) and East London Lines (http://www.eastlondonlines.co.uk). The process of documentation recorded multiple features, these included:

- the nature of the activity or business class - commercial general, commercial agricultural, commercial industrial, commercial non-industrial, health and education, leisure and tourism, retail, retail food, food and drink, transport.

- The floor or floors this activity was located on; i.e. ground, ground and first, first, etc.

- The name of the outlet

- The product(s) or services offered

- externally visible ethnic affiliation, e.g. Chinese takeaway, Turkish grocer, AfroCaribbean hairdresser discernible from visible shop signage on the exterior of the outlet. This method follows the system used in a study of an area of south London (Hall and Datta, 2010) and for an area of Athens (Vlachou and Vaughan, 2015).

- Whether the retailer was associated with a national chain (Tesco, Boots etc.), a smaller local chain (e.g. local designers with limited outlets and local charity outlets), or was an independent retailer.

- Whether space outside the commercial unit had been appropriated by the proprietor in any way, e.g. for the display of goods or seating, which in turn reflects a degree of interaction between the commercial unit and the public space (Kickert, 2016).

When recording on-site ethnicity, the intention was to record a more nuanced conception of ethnic presence on the high street than those provided by ONS statistics of residential population, which use broad groupings, such as a single group for 
'African'. Where available, the individual country of origin was recorded instead. This process was carried out in a similar way to the work by O'Brien on place of birth of residents, where a threshold of $8 \%$ of the total area population was used to determine the presence of a minority community, whilst assuming a background majority of UK British (O'Brien, 2016). ${ }^{1}$ Thus, if a retail unit was part of a national chain, ethnicity would not be recorded, if it was an independent where the services or goods are aimed at a particular ethnicity or ethnicities/religions, ethnicity would be recorded, and finally if it was an independent where the ethnicity of the proprietor was identifiable yet the services or goods offered are generic, ethnicity would not be recorded. Notably this differs from methods in studies of MEB business people and networks, where the background of the proprietor and their social/spatial relationship to the street would be relevant (Hall, 2013). In this instance of a desk-based study, with a focus on MEBs as a source of land use diversity, such data were deemed to be less relevant, though we do not exclude the option of making such explorations in any follow-up to this study. The researchers acknowledge that a certain level of detail may have been lost due to the observation-based process of documentation, as certain outlets may have used generic signage, whilst certain communities may intentionally seek to remain invisible in the public domain - an invisibility that may be attributed to local racial hierarchies (Knowles, 2013) - and hence not publicise their presence on the high street.

Summary statistics for the ten cases studied are presented in Table 1, which shows the spatial characteristics of each of the cases as well as the socio-economic character of their neighbourhood.

\footnotetext{
${ }^{1}$ https://maps.cdrc.ac.uk/\#/metrics/countryofbirth/default/BTTTFTT/10/-0.1500/51.5200/, accessed on 24 ${ }^{\text {th }}$ May, 2016.
} 


\begin{tabular}{|c|c|c|c|c|c|}
\hline Name & Socio-economic category & $\begin{array}{l}\text { Length } \\
(\mathrm{m})\end{array}$ & $\begin{array}{l}\text { No. of } \\
\text { Blocks }\end{array}$ & $\begin{array}{l}\text { No. of } \\
\text { units }\end{array}$ & $\begin{array}{l}\text { Avg. unit area } \\
(\mathrm{m})\end{array}$ \\
\hline Deptford High Street & $\begin{array}{r}\text { High Deprivation-High Ethnic } \\
\text { diversity }\end{array}$ & 417 & 11 & 114 & 114.39 \\
\hline Watling Avenue, Burnt Oak & $\begin{array}{r}\text { High Deprivation-High Ethnic } \\
\text { diversity }\end{array}$ & 318 & 8 & 92 & 99.61 \\
\hline Putney High Street & $\begin{array}{r}\text { Low Deprivation-Low Ethnic } \\
\text { diversity }\end{array}$ & 673 & 11 & 136 & 158.14 \\
\hline Wimbledon Village High Street & $\begin{array}{r}\text { Low Deprivation-Low Ethnic } \\
\text { diversity }\end{array}$ & 496 & 14 & 109 & 112.50 \\
\hline Walworth Road & $\begin{array}{r}\text { High Deprivation-Low Ethnic } \\
\text { Diversity }\end{array}$ & 503 & 12 & 136 & 179.96 \\
\hline Bethnal Green Road & $\begin{array}{r}\text { High Deprivation-Low Ethnic } \\
\text { Diversity }\end{array}$ & 450 & 14 & 114 & 111.98 \\
\hline The Broadway, Southall & $\begin{array}{r}\text { High Deprivation-Low Ethnic } \\
\text { Diversity }\end{array}$ & 470 & 12 & 164 & 149.15 \\
\hline High Street, Romford & $\begin{array}{r}\text { High Deprivation-Low Ethnic } \\
\text { Diversity }\end{array}$ & 505 & 8 & 65 & 232.32 \\
\hline St. John's Wood High Street & $\begin{array}{r}\text { Low Deprivation-High Ethnic } \\
\text { Diversity }\end{array}$ & 454 & 10 & 97 & 117.50 \\
\hline Station Road, North Harrow & $\begin{array}{r}\text { Low Deprivation-High Ethnic } \\
\text { Diversity }\end{array}$ & 404 & 11 & 83 & 140.17 \\
\hline
\end{tabular}

Table 1. Case study spatial characteristics.

\section{Analysis}

\section{Descriptive statistics}

Of the 1,108 units recorded across ten cases, 266 or $24 \%$ of the total number of recorded units were recorded as being visibly MEBs, namely with an externally visible ethnic affiliation such as Polish butcher (see explanation in 'Data Gathering', above). Further analysis of these businesses showed that MEBs seem to be of two types; those that provide a generic service such as the shop selling cheap plastic household products and luggage, the mobile phone and accessories store, the local internet cafe and the other being those businesses supplying specifically ethnic products such as clothing and fashion accessories, jewellery, hair and beauty services specific to a particular community, money transfer and exchange services, ethnic food and other services, such as legal advice for visa and immigration. This seems to be happening within the background of general services such as banks, opticians or estate agents, shoe repair and key cutting and retail outlets for national chain supermarkets. 
Keeping this in mind, MEBs on the high street are found primarily in three business classes (leaving only $2.4 \%$ of MEBs in other categories):

1. Retail (for example Madhan's Shopping Centre on Southall's high street, see Figure 2), $51.2 \%$ of all MEBs in the sample.

2. Retail food (such as Ha-Noi supermarket in Deptford), $19.4 \%$ of all MEBs

3. Food and drink (for example, Mori Sushi in St John's Wood), 27\% of all MEBs

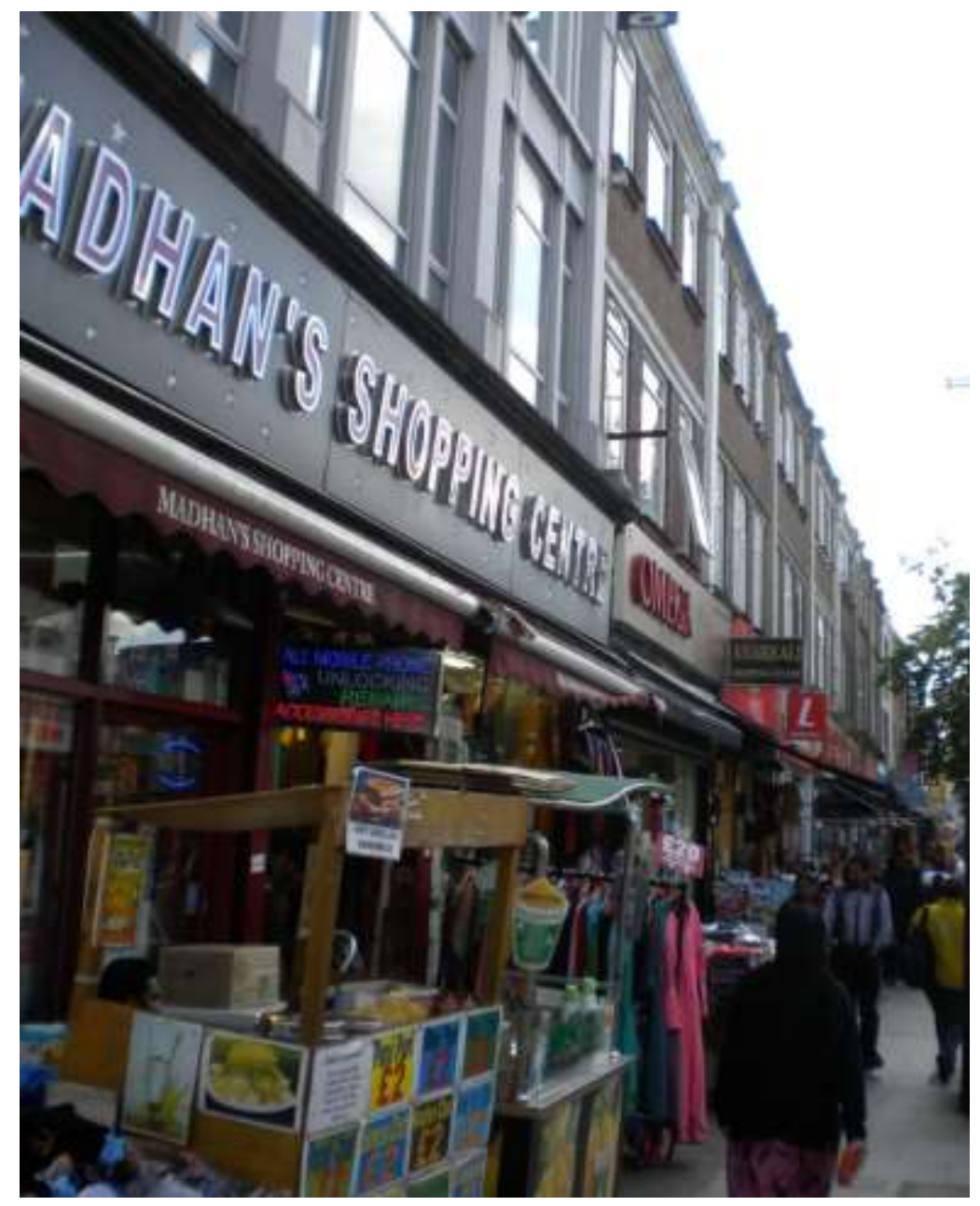

Figure 2. Madhan's Shopping Centre on Southall's high street, The Broadway. 
There were varying degrees of MEB concentration across the ten sites (see Figure 3, which shows the overall percentage of MEB units from all units in each high street studied). The percentages range from MEBs comprising over $50 \%$ of all units as is the case on Southall's Broadway, to just over $4 \%$ of all units in the case of St John's Wood High Street. Within this distribution it should be noted that North Harrow, Deptford High Street, Burnt Oak and Southall all have over $25 \%$ of recorded units visually identified as MEB. Three of the four latter cases were found to have a local population with a high degree of ethnic diversity: North Harrow, Deptford and Burnt Oak. The fourth, Southall, is predominantly South Asian with more than $50 \%$ visible MEB units;

- $\quad$ Locations with a high UK British presence, with a small presence of mainly food and drink outlets or other small MEB businesses, ranging from 4\% to 9.3\% (St. John's Wood, Putney, Romford and Wimbledon Village);

- High ethnic mix of local residential communities (Walworth Road, North Harrow, Deptford and Watling Avenue; though not Bethnal Green Road) with a paralleled diversity of MEB functions, ranging from $14.7 \%$ to $31.5 \%$;

- $\quad$ and the 'ethnic marketplace', where a single category of MEB businesses dominate, as in Southall, with over $50 \%$ units, and a parallel high presence of people from a South Asian background. 


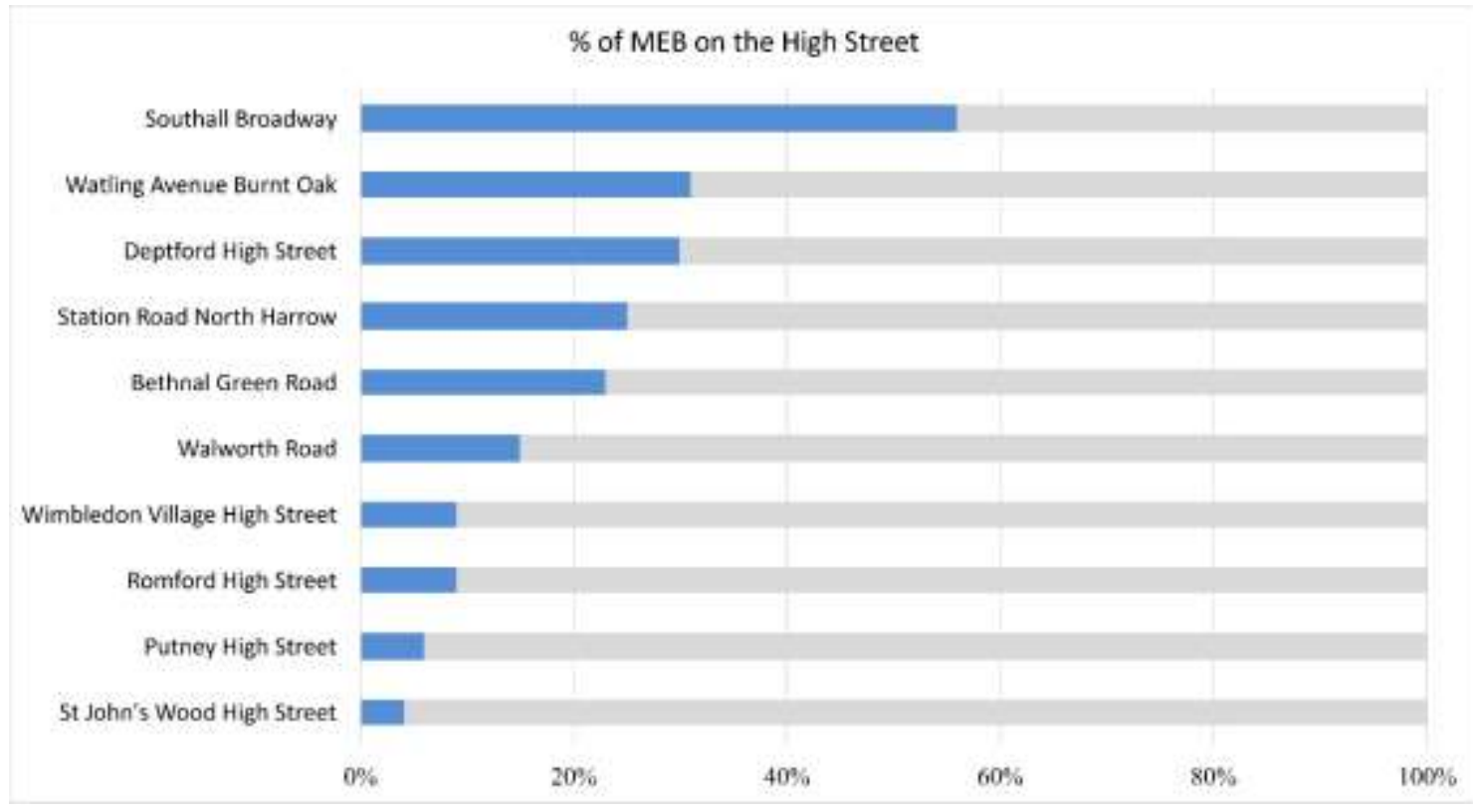

Figure 3. Percentage of high street units that are MEBs.

Preliminary analysis using space syntax methods to measure how accessible each high street was in relation to its surroundings found that high streets which contain a large number of minority ethnic businesses benefit from being located on streets that are central to their local neighbourhoods. This was particularly the case with high streets which had a significant ( $20 \%$ or more) presence of MEB units. We found that on the whole, high streets with a high MEB presence seem to be reasonably accessible at both the local and the regional scale, more often than not located on significant local/regional through routes of a locality (Vaughan et al, 2017). The findings support the proposition that minority ethnic commercial centres tend to be located 'physically near to the centre but perceptually distant from it' (Hall, 2011, p. 2572). This suggests that their high spatial integration allows for the footfall required for commercial viability whilst their perceptual location in the 'urban margins' provides an environment conducive to the emergence and presence of alternative cultures and economies. This is assessed further in the first section of the analysis, below. 
We also found that the average size of units containing MEB units was measurably smaller (112 sq. metres compared with 149 sq. metres for non-MEB units). This was supported by the fact that the largest areas appropriated by MEBs were in low ethnically diverse and low deprivation areas such as Wimbledon Village High Street and St. John's Wood High Street. Unlike the more ethnically diverse centres, in these cases they are mostly in the Restaurant and bar category. On the whole, the fact that ethnic businesses are measurably smaller, particularly in areas of high deprivation, might give rise to a greater diversity of activity and a greater presence of MEB units in areas where access to a good mix of affordable goods and services is especially important to people living in deprivation. This is assessed in the socio-economic exploration in the second part of the analysis, below.

The impact of minority ethnic business diversity on the commercial diversity of a town centre

Building on the preliminary analysis described above, the following explores Hypothesis 1: that high MEB presence and diversity has a positive impact on the commercial diversity of a local town centre. In order to test this hypothesis, a diversity index was constructed based on data available for each high street block in the case study areas. Diversity indexing is commonly used in ecological studies to measure the diversity of species in a community. In this study we adopted this measure to identify the composition of high street blocks in terms of their land use types and MEBs. Hence, for every high street block, the land use diversity and MEB diversity were both calculated using the Shannon-Wiener Diversity Index, which reflects how many species (or land use types in this instance) there are within an area (a sampled high street block in this instance). It measures the distribution such that a perfectly homogenous distribution of activities along a given number of categories would have a maximum diversity. If there is only one activity present, there is no diversity by this measure. For a full description of the formula and its background, see Dhanani et al, 2017.

Higher scores of diversity are indicative of more and diverse land use (or MEB) presence in the given block and a score closer to 0 indicates presence of a small number of land use types (i.e. a single building with one land use type within a block face) or in the case of MEB, a block face where no MEB business is present. As an example consider 
the following calculation for one of the urban blocks of the high street composed of twelve buildings. Tables 2 and 3 show how we calculated the commercial diversity (Table 2) and MEB diversity (Table 3 ) for a single block within one of the cases, Bethnal Green Road while Figure 4 shows the classification of all the units in the Bethnal Green Road case. The tables show that in this particular urban block nine different categories of products are sold, of which around $40 \%$ are minority ethnic businesses. Overall, this urban block has both high commercial diversity and high MEB diversity. 


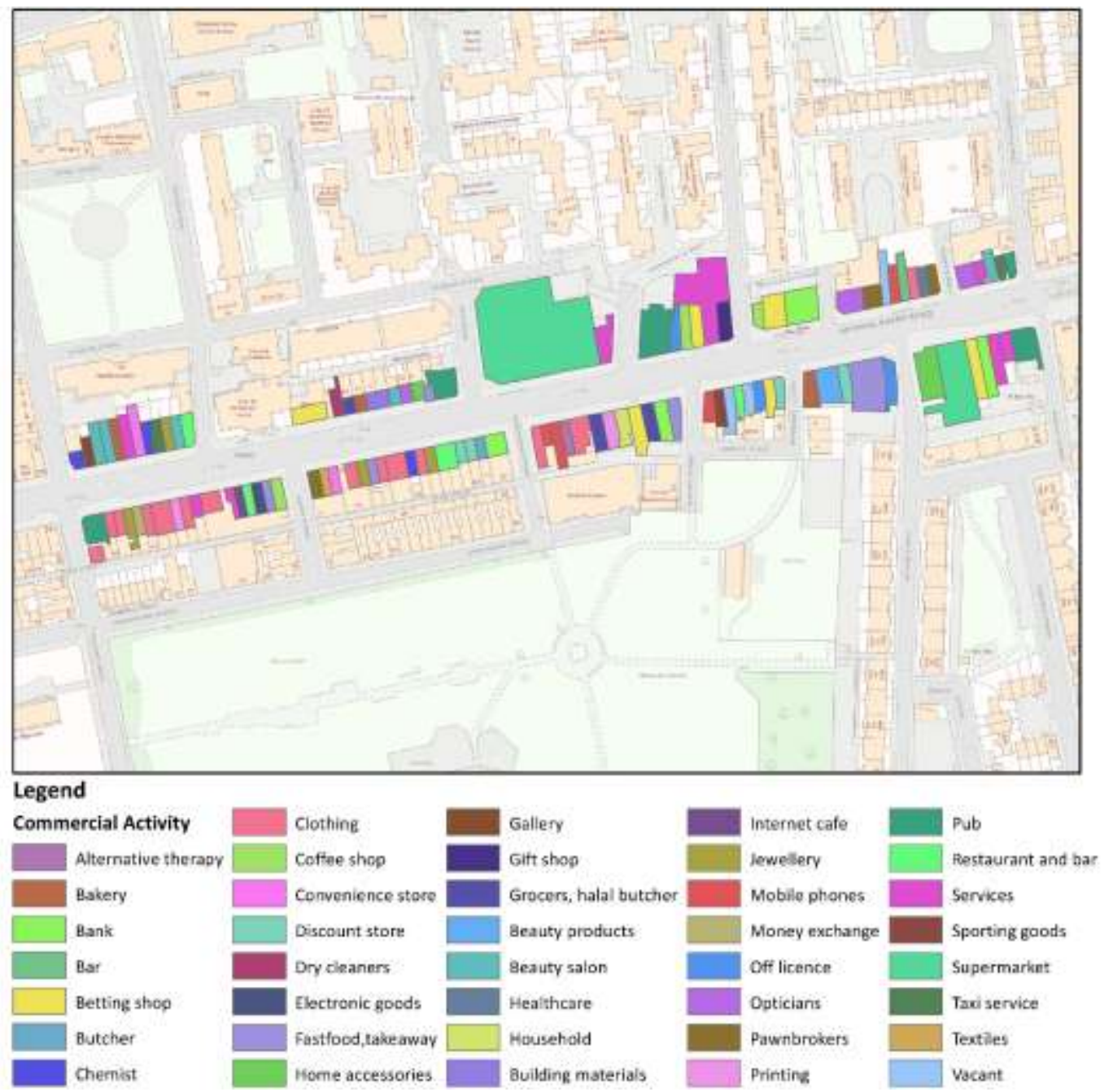

This is a post-peer-review, pre-copyedit version of an article published in Urban Design International. The final authenticated version is available online at: https://doi.org/10.1057/s41289-018-0060-5. (C) The authors, UCL. 

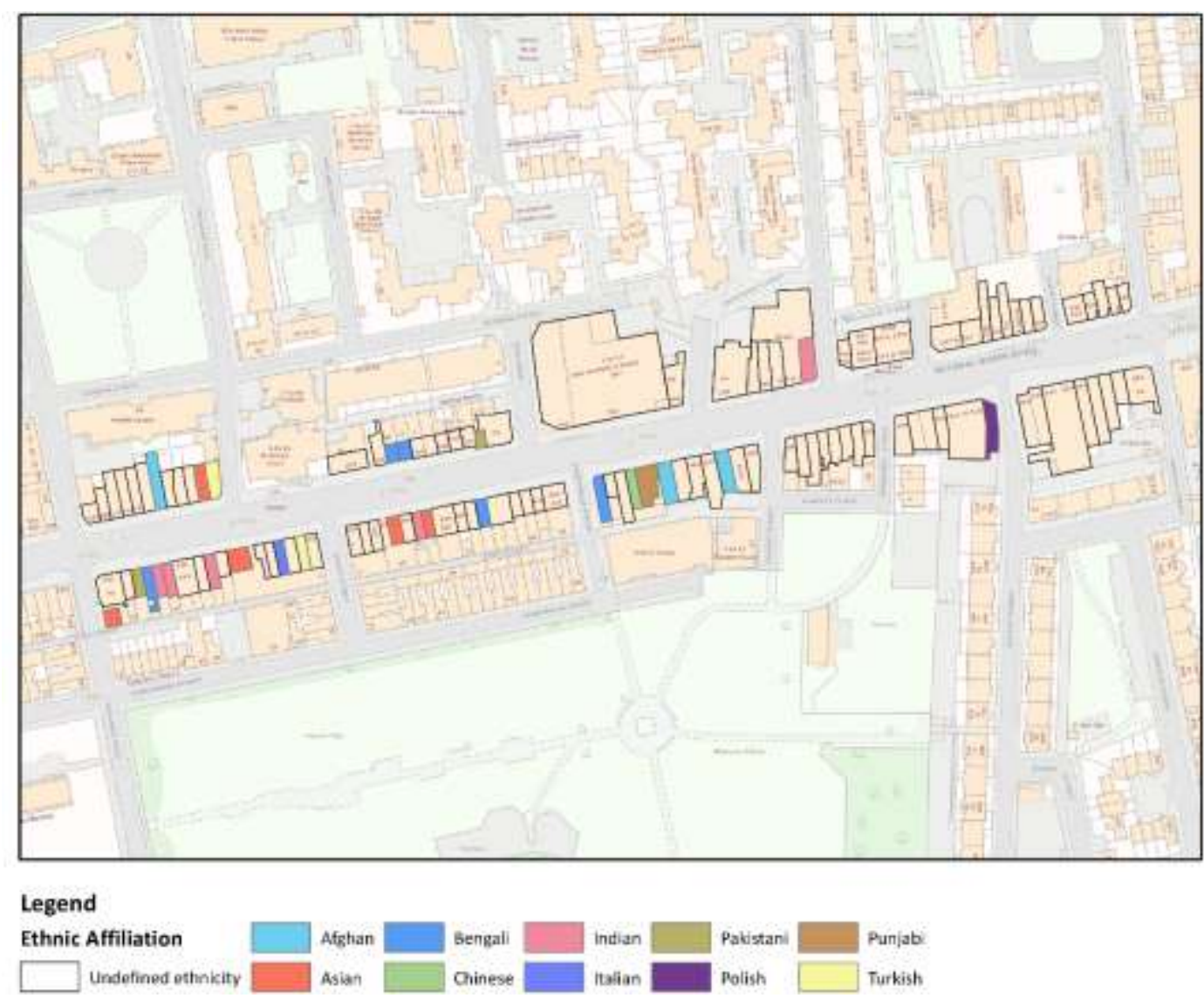

Figure 4. Example of mapping of diversity for the case of Bethnal Green Road. Top: Commercial diversity; bottom: Ethnic diversity

\begin{tabular}{|c|c|c|c|c|c|}
\hline Product types & $\begin{array}{r}\text { Count of product } \\
\text { types (no) }\end{array}$ & $\begin{array}{r}\text { Relative abundance } \\
\text { (pi) }\end{array}$ & In pi & $\mathrm{pi}(\ln \mathrm{pi})$ & $\begin{array}{r}\text { Shannon's } \\
\text { Diversity }\end{array}$ \\
\hline Alternative therapies & 1 & 0.083 & -2.485 & -0.207 & \\
\hline Bank & 1 & 0.083 & -2.485 & -0.207 & \\
\hline Betting Shop & 1 & 0.083 & -2.485 & -0.207 & \\
\hline Clothing & 2 & 0.167 & -1.792 & -0.299 & 2.138 \\
\hline $\begin{array}{l}\text { Fast-food \& } \\
\text { Takeaway }\end{array}$ & 1 & 0.083 & -2.485 & -0.207 & \\
\hline $\begin{array}{l}\text { Grocers, Halal } \\
\text { Butcher }\end{array}$ & 2 & 0.167 & -1.792 & -0.299 & \\
\hline
\end{tabular}




$\begin{array}{lrrrr}\text { Household } & 1 & 0.083 & -2.485 & -0.207 \\ \text { Mobile phones and } & 2 & 0.167 & -1.792 & -0.299 \\ \text { accessories } & 1 & 0.083 & -2.485 & -0.207 \\ \text { Printing } & 12 & - & -\end{array}$

Table 2. Example of diversity calculation of land uses for a single urban block on the high street.

\begin{tabular}{lrrrrr} 
Ethnicity & $\begin{array}{r}\text { Count of ethnicity } \\
\text { types (no) }\end{array}$ & $\begin{array}{r}\text { Relative abundance } \\
\text { (pi) }\end{array}$ & In pi & pi(In pi) & Shannon's Diversity \\
\hline Afghan & 2 & 0.167 & -1.792 & -0.299 & \\
Bengali & 1 & 0.083 & -2.485 & -0.207 & \\
Chinese & 1 & 0.083 & -2.485 & -0.207 & 1.234 \\
Undefined ethnicity & 7 & 0.583 & -0.539 & -0.314 & -0.207 \\
Punjabi & 1 & 0.083 & -2.485 & -
\end{tabular}

Table 3. Example of diversity calculation of minority ethnic land uses for a single urban block on the high street.

When the total commercial diversity across all high street blocks is plotted against MEB diversity (Figure 5), a positive upward relationship between the two can be identified. Although there are street sections that have high commercial diversity without any MEB presence (i.e. MEB diversity score equals 0 ), it is evident that those urban blocks which have minority ethnic businesses, have equal or even more commercially diversity than those without any MEB. Moreover, higher MEB diversity corresponds to greater commercial diversity. This is indicative that the MEB presence brings a bigger range of products and services to the high street. 


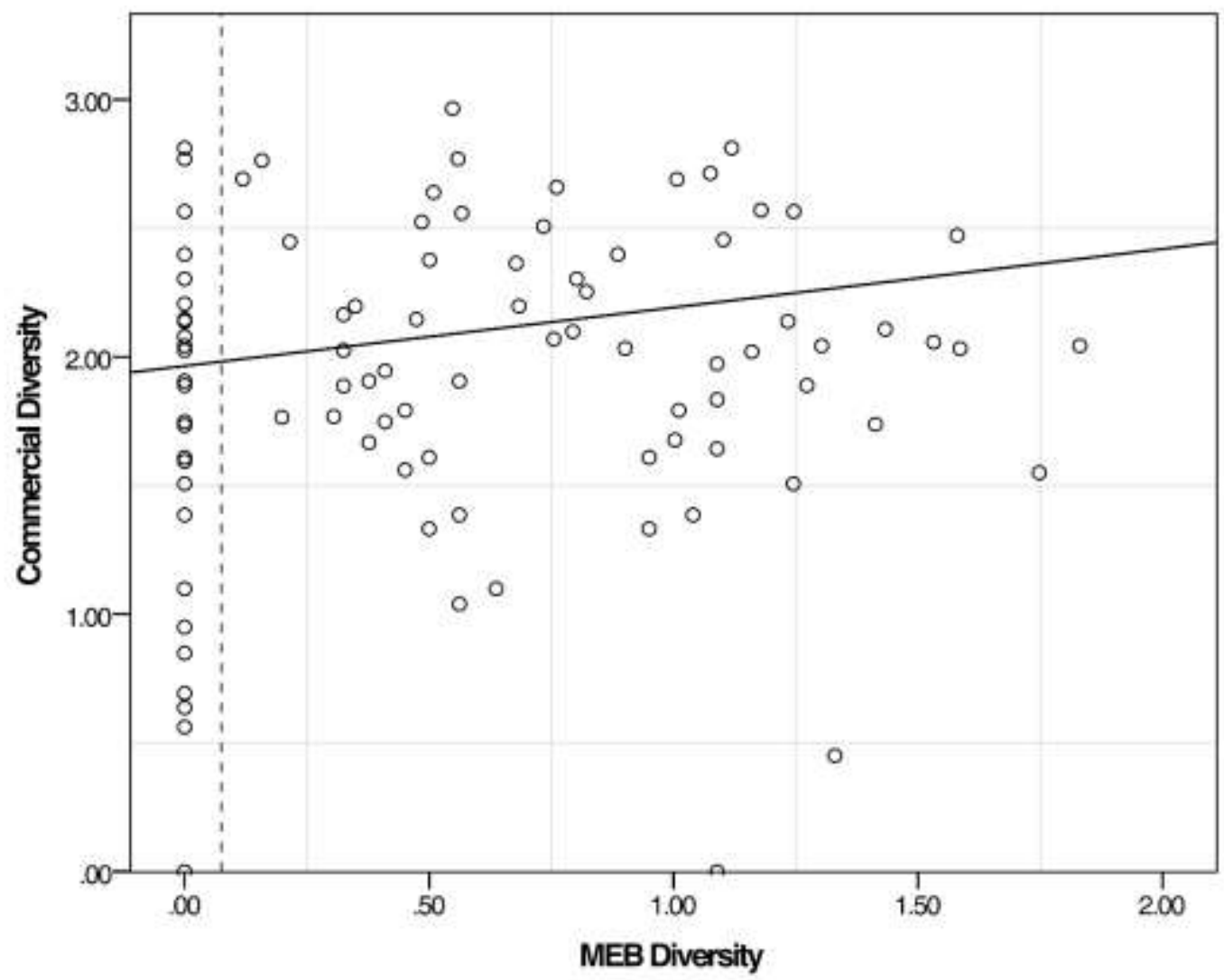

Figure 5. A plot of commercial diversity against MEB diversity for urban blocks on the high street.

We then used a regression model to establish whether there is a statistical relationship between MEB diversity and commercial diversity. Here the dependent variable was the commercial diversity calculated at block level and the independent or predictive variable was the MEB diversity. Given the spatial nature of the data, spatial regression was used for statistical purposes, namely an equation which takes account of the spatial interaction expressed as a distance between street blocks, where blocks closer to each other could potentially be more similar in their composition than the ones further apart from each other. The results showed a strong positive statistical evidence in favour of 
Hypothesis $1 .^{2}$ This signifies that the presence of minority ethnic businesses positively affects the commercial diversity along a high street; moreover, more MEB diversity brings more commercial diversity to the area. Importantly, this calculation takes account of proximity between use types within a block, so considers clustering of types. The implications of this result will be discussed below.

\section{The relationship between minority ethnic business diversity in a town centre and the amount of deprivation of the population in its vicinity}

The following section explores the hypothesis that a high instance of MEB businesses corresponds to a relatively deprived population within walking distance (up to $2000 \mathrm{~m}$ ) from a high street.

As stated earlier in this paper, MEBs are to be found primarily in three land use classes: Retail, Retail Food and Food and Drink. A more detailed unpacking of where MEBs are clustering within these broad classes can be found in Figure 6, which shows the frequency distribution of 67 land use types across the 10 case studies. It shows that first, MEBs are to be found in only 38 of the 67 sub-classes found across the cases. It also shows that in contrast with the national chains stores commonly found on UK high streets, such as betting shops, banks, estate agents, hardware stores or charity shops, most MEBs are in sub-classes that are not otherwise occupied by chain or franchise retailers - either offering niche goods (such as halal butchers) or niche services (such as African hairdressers). The fact that minority ethnic businesses tend not to be chain outlets is suggestive of an approach to MEB ownership that prefers to find - or create niche markets, rather than to compete with the mainstream.

\footnotetext{
${ }^{2}$ In the regression model estimation for hypothesis N1, the dependent variable is commercial diversity and the unit of analysis is urban blocks).). Here the intercept is 1.02, which indicates that on average every urban block has 1.02 units of commercial diversity with the added contribution of 0.13 for every unit increase in MEB diversity. Sample size $n=1,108 ; p<.001$.
} 


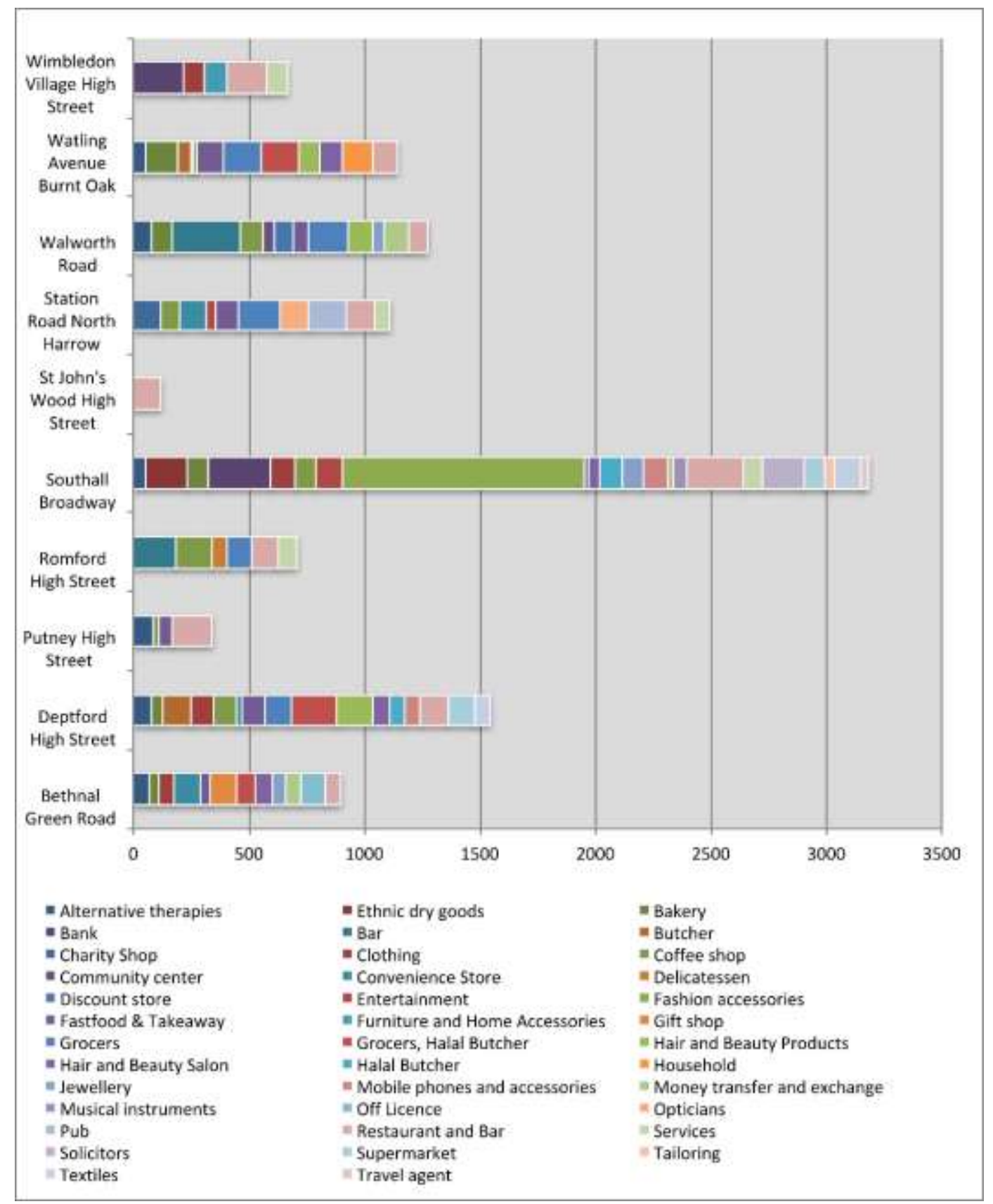

Figure 6. Comparative distributions of MEB land uses across the sample.

This is a post-peer-review, pre-copyedit version of an article published in Urban Design International. The final authenticated version is available online at: https://doi.org/10.1057/s41289-018-0060-5. (C) The authors, UCL. 
In the following we analysed the social make-up of the population living within 2000 metres away from the high streets. This was then set against the other data, as seen in the table below. When the three MEB groups (ethnic market, mixed and the background group, namely no specific group) were tested statistically, no correspondence was found between the ethnic diversity of the surrounding population and percentage of MEB units, nor was there a correspondence between the IMD (deprivation) of the surrounding population and the percentage of MEB units (see Table 4). This might be due to the small sample within each grouping, but the lack of variation in the ethnicity of the background population is also likely to be related to London itself having a high rate of ethnic diversity in most of its urban areas.

\begin{tabular}{|l|l|r|r|r|}
\hline \multirow{3}{*}{$\begin{array}{l}\text { Ethnic } \\
\text { market }\end{array}$} & Locality & \% of MEB units & $\begin{array}{r}\text { Ethnic diversity } \\
(2000 \mathrm{~m} \text { locality })\end{array}$ & $\begin{array}{r}\text { IMD Index } \\
(2000 \mathrm{~m} \text { locality })\end{array}$ \\
\hline \multirow{4}{*}{ Mixed } & Southall Broadway & 56.10 & 0.67 & 28.68 \\
\cline { 2 - 5 } & Watling Avenue Burnt Oak & & & \\
\cline { 2 - 5 } & Deptford High Street & 31.52 & 0.70 & 20.38 \\
\cline { 2 - 5 } & Station Road North Harrow & 30.70 & 0.65 & 27.60 \\
\cline { 2 - 5 } & Bethnal Green Road & 25.30 & 0.66 & 13.15 \\
\hline \multirow{4}{*}{$\begin{array}{l}\text { UK } \\
\text { British }\end{array}$} & Walworth Road & 22.81 & 0.61 & 35.86 \\
\cline { 2 - 5 } & Wimbledon Village High Street & 14.71 & 0.67 & 33.21 \\
\cline { 2 - 5 } & Romford High Street & 9.26 & 0.49 & 8.91 \\
\cline { 2 - 5 } & Putney High Street & 9.23 & 0.32 & 18.12 \\
\cline { 2 - 5 } & St John's Wood High Street & 6.67 & 0.51 & 16.68 \\
\hline
\end{tabular}

Table 4. Percentage of MEB units on the high street in relation to socio-economic background of the surrounding area.

While there was no direct correlation between MEB presence on a high street and the deprivation or indeed the ethnic diversity of the high street's background population, further statistical testing using ANOVA found that the differences in the MEB presence across the three notional groups (UK British, Mixed and 'Ethnic Market') was statistically 
significant. ${ }^{3}$ This shows that the groups are dissimilar in their composition of MEB units, supporting the proposition made elsewhere that there are in fact three distinct types of ethnic marketplaces (Vaughan, 2015b), ranging from a small-scale presence on an otherwise mainstream high street, to the type of high street typified by Southall Broadway, that not only serves its local South Asian population, but attracts Londoners from across the city. The 'ethnic marketplace', we argue, provides a form of engagement with a person's home culture at critical points in their daily life, allowing people to maintain a hybrid identity (such as Asian British).

The need to consider identity when analysing the urban morphology of minority ethnic business is not trivial. In a detailed study by Nasser (2004) of Southall's morphological and socio-economic evolution, the author found that Southall's high street has evolved from being a prosaic suburban commercial centre, with Victorian and Edwardian buildings, into a distinct kaleidoscope ('Kaleido-scape') of purpose-built buildings and organisations which support a multiplicity of identities for which a simple labelling as 'South Asian' might be viewed as somewhat reductive. Importantly, Nasser shows how the shop fronts highlight this variety, with business names and language scripts ranging from English, Punjabi, Arabic to Urdu (op cit., p. 97), creating a 'new hybrid urban morphology that combines local vernaculars with global (or imported) elements (op cit. p., 100).

Another notable point for Southall is that charity shops are often seen as indicators of decline. While 25 units were identified across the 10 cases, they varied in their character. In the case of Bethnal Green Road, the single charity shop serves a local cause, the Spitalfields Crypt Trust, as opposed to the national charity shops found in other areas. The absence of charity shops in areas with high South Asian presence/faith-based communities may have to do with the fact that such services are often managed by the local mosque, temple or gurdwara. Another interesting feature that comes to light is low deprivation areas like Putney High Street and Wimbledon Village High Street house are more likely to contain national charities like Cancer Research UK, Oxfam and the British Heart Foundation; more local charities seem to set

\footnotetext{
$\left.{ }^{3} F(1,7)\right)=47.741, \mathrm{p}=.001$
} 
up shop on high streets in high deprivation areas like the aforementioned Spitalfields Crypt Trust on Bethnal Green Road, the Deptford Action Group for the Elderly on Deptford High Street, and the Trinity Hospice on Walworth Road.

Another aspect of deprivation was found when analysing the location of money exchange/transfer outlets. We found that most units identified in the sample areas shared space with other services, ranging from internet cafes to mobile phone accessories, to hair and beauty salons, to garments. Interestingly, the highest concentration of money exchange/transfer facilities were to be found in areas that are classified as low ethnic diversity but where the dominant ethnic presence was that of communities that would otherwise be perceived as an ethnic minority, with six units to be found in both Southall (Asian/Indian) and Walworth Road (Black/African).

\section{Discussion and conclusions}

Suzanne Hall's research into ethnicity and retail practices in minority ethnic high streets has suggested that there is a need for specific forms of planning to support the growth of small, independent shops and local high streets (Hall, 2011, 2013). She has also demonstrated that there are specific practices by small shopkeepers that allow them to operate in areas of high deprivation and to compete with national companies. This paper has taken her approach to fine-grained social research into retail practices and applied similarly fine-grained spatial research to explore the character of MEB high streets. It has shown that, of the 1,108 units recorded across ten cases, 266 or $24 \%$ of the total number of recorded units were visibly MEBs. We have found evidence to support Hypothesis 1: there is a strong correlation between MEB diversity and commercial diversity, which is a measure of the economic vitality that MEB businesses can bring to a town centres. We also found that the size of MEB business units was measurably smaller than non-MEB units, suggesting that the morphology of the built environment can itself support a diversity of land uses, as another study of smaller suburban town centres has found (Vaughan, 2015a).

The analysis did not find evidence to support a correspondence between MEB diversity and the amount of deprivation in the background population (Hypothesis 2). 
Nevertheless, the residential population living around the cases selected exhibits the full spectrum of varying ethnic diversity to be found in London's residential neighbourhoods: at one end of the spectrum low ethnic diversity in an area implies high UK British presence, the spectrum then shifts to incorporate areas that exhibit a high ethnic mix of communities, and finally there appears to be a third category, comprising mono-ethnic areas where the ethnic diversity of the area may be low but the dominant background presence is that of a minority ethnic community. These findings are further supported by the percentage of MEB units to be found in these areas, where Southall's background South Asian population is served by what may be considered an 'ethnic market' where over $50 \%$ of commercial units recorded were MEBs, whilst Putney, Romford and Wimbledon Village High Street occupy the other end of the spectrum with less than $10 \%$ of commercial units recorded as MEBs.

The analysis has also shown that MEBs are to be found primarily in three land use classes - Retail, Retail Food and Food and Drink. It was seen that in affluent areas with low neighbourhood ethnic diversity such as Wimbledon Village and Putney, the distribution of MEBs across these three categories was skewed in favour of the Food and Drink class with limited or no MEB presence in the Retail Food class. Where neighbourhood ethnic diversity was higher, there was a greater MEB presence in both the Retail and Retail Food class. This finding seems to indicate two things: first, that where there is an embedded minority ethnic neighbourhood presence there is a more diverse MEB presence and second, that there is an association (but not a strong correlation) between both minority ethnic neighbourhood presence, MEB presence on the high street, and deprivation.

As mentioned above, minority ethnic businesses are likely to occupy smaller units in comparison to non-MEB units. The analysis testing the association between MEB diversity and general commercial diversity found that the former encourages the latter. There is also a greater diversity of products within the areas of high deprivation. This may be to the benefit of a poorer population; not only in providing cheaper goods, but more different sorts of goods and services within reach on foot - as well as more opportunities for local employment. Taking all this into account, we argue that the morphological structure of the high street blocks can create an opportunity for commercial diversity. Indeed, the analysis of background deprivation strengthens the 
argument that commercial diversity is a factor that can support people living in deprivation, from whatever ethnic background.

Finally, this study's results show that a relatively small number of units can have a significant effect on the composition of the high street and can contribute to its longterm sustainability. This conclusion is supported by studies done in the US and Australian contexts, which have found that street width and continuity, lot configuration within the block, building size, and land use mixing can contribute to the longevity of a town centre (see e.g. Scheer and Ferdelman, 2001, p. 20). Putting all the evidence together, we conclude that minority ethnic high streets have measurable spatial characteristics that stem from their location in particularly accessible locations within the street network, in buildings that lend themselves to adaptation and in frontages that are amenable to a wide variety of activities to take place within close proximity. We have evidence to show that minority ethnic business high streets provide many of the features of sustainability highlighted by Penn and colleagues (2009) cited at the start of this paper: a greater diversity of uses that provides for greater opportunities for social and informational exchange that is to the benefit of both the business owners and their customers.

Emily Talen has quoted Peter Hall's observation that the most potent manifestations of non-diversity are problems that, "almost unbelievably", city planning has not been called upon to answer (Hall, 2002, cited in Talen, 2010). We would argue in a similar vein that urban planning and design have a role to play in sustaining examples of positive socio-economic diversity that is too easily dismissed as the uncongenial outcome of a lack of investment, when the reality is that it can be a sign of a highly dynamic instance of urban sustainability.

\section{Limitations}

This study has relied primarily on quantitative analysis and has focused on a sample of high streets in London which may not be representative of cities elsewhere in the UK, not only because of the UK capital's size, but also because of its character of high ethnic diversity, withpockets of high deprivation situated alongside high prosperity. 
Nevertheless, we have provided evidence for the importance of the minority ethnic business both for the economic infrastructure of an area, but also in providing less tangible benefits, such as sources of information or support for a population living in deprivation.

\section{Acknowledgement}

This paper was produced with funding from the Street Mobility and Network Accessibility research project, which was supported by the UK Engineering and Physical Sciences Research Council (EPSRC), Economic and Social Research Council (ESRC), and Arts and Humanities Research Council (AHRC) [grant number EP/K037323/1].

\section{References:}

Aldrich H., Cater J., Jones T., Evoy D. M., and Velleman P. (1985) Ethnic Residential Concentration and the Protected Market Hypothesis, Social Forces, 63, 996-1009

Astbury G., and Thurstain-Goodwin M. (2014) Measuring the Impact of Out-of-Town Retail Development on Town Centre Retail Property in England and Wales, Applied Spatial Analysis and Policy, 7, 301-316

Barrett G. A., Jones T. P., and McEvoy D. (1996) Ethnic Minority Business: Theoretical Discourse in Britain and North America, Urban Studies, 33, 783-809

Department for Business Innovation and Skills, Genecon LLP and Partners, and Urban Pollinators (2011) Understanding High Street Performance. BIS, London

Dhanani A., Tarkhanyan L., and Vaughan L. (2017) Estimating Pedestrian Demand for Active Transport Evaluation and Planning, Transportation Research Part A: Policy and Practice, 103, 54-69

Dobson J. (2016) Rethinking Town Centre Economies: Beyond the 'Place or People' Binary, Local Economy, 31, 335-343 
Frank L. D., Schmid T. L., Sallis J. F., Chapman J., and Saelens B. E. (2005) Linking Objectively Measured Physical Activity with Objectively Measured Urban Form Findings from Smartraq, American Journal of Preventive Medicine, 28: 117-125.

Gort Scott, and UCL Bartlett School of Planning (2010) High Street London. Design for London, Greater London Authority, London, London

Griffiths S., Vaughan L., Haklay M., and Jones C. E. (2008) The Sustainable Suburban High Street: Themes and Approaches, Geography Compass, 2, 1155-1188

Hall P. (2002) Cities of Tomorrow: An Intellectual History of Urban Planning and Design in the Twentieth Century, 3rd Edn. Oxford: Blackwell

Hall S. M., and Datta A. (2010) The Translocal Street: Shop Signs and Local Multi-Culture Along the Walworth Road, South London, City, Culture and Society, 1, 69-77

Hall S. M. (2011) High Street Adaptations: Ethnicity, Independent Retail Practices, and Localism in London's Urban Margins, Environment and Planning A, 43, 2571-2588

Hall S. M. (2013) Super-Diverse Street: A 'Trans-Ethnography' across Migrant Localities, Ethnic and Racial Studies, 38, 1-14

Hiebert D., Rath J., and Vertovec S. (2014) Urban Markets and Diversity: Towards a Research Agenda, Ethnic and Racial Studies, 38, 5-21

Hillier B. (1999) Centrality as a Process: Accounting for Attraction Inequalities in Deformed Grids, Urban Design International, 4, 107-127.

Iyer G. R., and Shapiro J. M. (1999) Ethnic Entrepreneurial and Marketing Systems: Implications for the Global Economy, Journal of International Marketing, 7, 83-110

Jones P., Roberts M., and Morris L. (2007) Rediscovering Mixed-Use Streets: The Contribution of Local High Streets to Sustainable Communities. Joseph Rowntree Foundation \& Polity Press, London

Kickert C. C. (2016) Active Centers-Interactive Edges: The Rise and Fall of Ground Floor Frontages, Urban Design International, 21, 55-77 
Kloosterman R., Van der Leun J., and Rath J. (1999) Mixed Embeddedness:(in) Formal Economic Activities and Immigrant Businesses in the Netherlands, International journal of Urban and Regional Research, 23, 252-266

Knowles C. (2013) Nigerian London: Re-Mapping Space and Ethnicity in Superdiverse Cities, Ethnic and Racial Studies, 36, 651-669

Legeby A. (2010) From Housing Segregation to Integration in Public Space: A Space Syntax Approach Applied on the City of Södertälje, The Journal of Space Syntax, 1, 92107

Marcus L., and Colding J. (2014) Toward an Integrated Theory of Spatial Morphology and Resilient Urban Systems, Ecology and Society, 19,

Nasser N. (2004) Southall's Kaleido-Scape: A Study in the Changing Morphology of a West London Suburb, Built Environment, 30, 76-103

O'Brien O. (2016) A Map of Country of Birth across the UK. Retrieved on 5th July/16 2016 from: http://oobrien.com/2016/05/countryofbirth/.

Paccoud A. (2013) Country of Birth in the 2011 Census: Local Authorities and London's Extended Metropolitan Region. LSE Cities Working Paper London

Penn A., Perdikogianni I., and Mottram C. (2009) Chapter 11: The Generation of Diversity, in: Cooper R., Evans G. and Boyko C. eds Designing Sustainable Cities: Decision-Making Tools and Resources for Design. Wiley Blackwell: Chichester 219-237

Perdikogianni I., and Penn A. (2006) Is Urban Diversity Synonymous with Urban Sustainability? What Do People "Suggest" for Clerkenwell in London? 2006 Annual General Conference of the Canadian Society for Civil Engineering, Calgary, Canada

Sarkar C., Gallacher J., and Webster C. 2013. Built Environment Configuration and Change in Body Mass Index: The Caerphilly Prospective Study (CaPS), Health \& Place 19: 33-44.

Scheer B. C., and Ferdelman D. (2001) Inner-City Destruction and Survival: The Case of over-the-Rhine, Cincinnati, Urban Morphology, 5, 15-28 
Talen E. (2010) The Context of Diversity: A Study of Six Chicago Neighbourhoods, Urban Studies, 47, 486-513

Törmä I., Griffiths S., and Vaughan L. (2017) High Street Changeability: The Effect of Urban Form on Demolition, Modification and Use Change in Two South London Suburbs. Urban Morphology, 21, 5-28

Vaughan L. (2007) The Spatial Syntax of Urban Segregation, Progress in Planning, 67, 199-294

Vaughan L. (2015a) Chapter 7: High Street Diversity, in: Vaughan L. ed Suburban Urbanities: Suburbs and the Life of the High Street. UCL Press: London 153-174

Vaughan L. (2015b) The Ethnic Marketplace as Point of Transition, in: Kershen A. ed London the Promised Land Revisited. Ashgate: Farnham, Surrey 35-54

Vaughan L., Sultan Khan S., Tarkhanyan L., and Dhanani A. (2017) The Spatial Configuration of Minority Ethnic Business Diversity in London's High Streets. In: Proceedings of the 11th International Space Syntax Symposium. University of Lisbon, Lisbon, Portugal

Vertovec S. (2006) The Emergence of Super-Diversity in Britain. Centre of Migration, Policy and Society, University of Oxford, Oxford, 25

Vlachou A., and Vaughan L. (2015) Successional Segregation in Gerani, Athens. Unpacking the Spatial Structure of an Immigrant Quarter. Proceedings of the 10th International Space Syntax Symposium. University College London, London Watson S. (2009) The Magic of the Marketplace: Sociality in a Neglected Public Space, Urban Studies 46: 1577-1591 